Research Article

\title{
Dispersant for Reducing Mud Cakes of Slurry Shield Tunnel Boring Machine in Sticky Ground
}

\author{
Shisen Zhao $(\mathbb{D}$, Shuchen Li $(\mathbb{D}$, Zeen Wan $(\mathbb{D}$, and Manling Wang $\mathbb{1}$ \\ School of Qilu Transportation, Shandong University, Jinan 250002, China \\ Correspondence should be addressed to Shuchen Li; shuchenli@sdu.edu.cn
}

Received 29 January 2021; Accepted 26 March 2021; Published 9 April 2021

Academic Editor: Luigi Di Sarno

Copyright ( $\odot 2021$ Shisen Zhao et al. This is an open access article distributed under the Creative Commons Attribution License, which permits unrestricted use, distribution, and reproduction in any medium, provided the original work is properly cited.

\begin{abstract}
When a slurry shield tunnel boring machine (TBM) encounters sticky ground during tunneling, mud cakes often occur on the cutter head due to the high stickiness of soil. The mud cakes caused several negative issues, such as high torque demand, advancement rate reduction, and additional costs. Existing studies have largely focused on Earth pressure balance TBMs; research on formation and mitigation measures of mud cakes in slurry shield TBMs is limited. Therefore, this study proposes the addition of dispersant to the slurry to prevent mud cakes during the tunneling of slurry shield TBMs by reducing stickiness of excavated clay. The basic properties of slurry were measured experimentally, and the effectiveness of dispersant in reducing the potential for mud cakes was investigated through mixing tests and viscosity experiments. A statistical analysis of the data was performed to determine relationships between slurry properties and material behaviors. The results showed that the slurry with dispersant had a lower viscosity and formed filter cakes more quickly, thereby meeting the performance requirements of a supporting fluid for slurry shield TBMs. Further, dispersant effectively reduced the empirical stickiness ratio and suspension viscosity. Therefore, a slurry with an appropriate dispersant content could effectively reduce the potential for mud cake formation.
\end{abstract}

\section{Introduction}

Slurry shield tunnel boring machines (TBM) provide for mechanized tunneling and are widely used in saturated strata. Slurry shield TBM is suitable for sand strata with permeability coefficients of $10^{-7}-10^{-4} \mathrm{~m} / \mathrm{s}[1,2]$. However, TBM tunnels almost always encounter sticky ground due to strata complexity and variability. Tunneling in the sticky ground results in mud cakes on the cutter head [3]. The Nanjing Yangtze River Tunnel, Yangzhou Slender West Lake Tunnel, and Wuhan Metro Line 8 Cross Yangtze River Tunnel projects all experienced mud cakes. This issue has several negative impacts, including high torque demand from the TBM, drastic reduction in performance, decrease in the advancement rate, lengthy and frequent interventions to clean the cutter head, and additional excavation costs [4]. Procedures such as eliminating the mud cakes using high pressure and adding high-pressure water jets can address the mud cakes, but these mitigation measures are inefficient.
The stickiness of the excavated clay is the primary factor that determines the potential for mud cakes. There are two main methods for evaluating the stickiness of excavated clay to assess the potential of mud cake formation. The first is based on the Atterberg limits and data from engineering experience. Thewes [3] proposed a method to analyze clay soil adhesion during slurry shield tunneling and evaluated the potential of mud cake formation based on the consistency and plasticity indices. Subsequently, Thewes and Burger [5], Hollmann and Thewes [6], and Thewes and Hollmann [7] further refined this method and extended its application to different shielding modes; this method is widely used to estimate mud cake risk. However, this method cannot quantify the effects of soil conditioners.

The second assessment method is based on the adhesion between the clay soil and the tools. Feinendegen et al. [8] proposed a "cone pull-out test" to determine the probability that clay soil will cause clogging. Zumsteg and Puzrin [9] proposed an empirical stickiness ratio measured using a Hobart mortar mixer with a B-flat beater to characterize the 
stickiness of clay and evaluate its clogging potential. Zumsteg et al. [10] researched the relationships between the ratios of adhesion to strength, consistency index, and empirical stickiness ratio. Additionally, Peila et al. [11] developed a dynamic and static lateral adhesion test system and analyzed the effect of a conditioner. Zumsteg et al. [12] combined the empirical stickiness ratio and a TBM cutterhead test to analyze the effects of carboxymethyl cellulose (CMC) on controlling the adhesion between clay and the cutter head of a slurry shield TBM. De Oliveira et al. [13] combined the consistency index, empirical stickiness ratio, and the method proposed by Thewes [3] to provide a possible method for assessing the efficiency of soil conditioners.

The stickiness of the excavated clay can be affected by the composition of the supporting slurry. A Na-bentonite slurry is typically used in a slurry shield TBM owing to its many favorable characteristics; however, pure Na-bentonite slurry does not prevent mud cakes, as evidenced by the mud cakes of many slurry shield TBM projects that utilized pure $\mathrm{Na}$ bentonite slurry. Therefore, pure Na-bentonite slurry should be treated with additives in some special cases to enhance slurry properties [12]. Guglielmett et al. [14] summarized the various types of polymers that can be added to the slurry, such as flocculants, dispersants, and CMC, and analyzed the fundamental mechanisms of their effects on slurry properties. Zumsteg et al. [10] studied the law of polyamine chemicals in Earth pressure balance (EPB) TBM tunneling to reduce adhesion, and Zumsteg et al. [12] investigated the effect of CMC on clogging of slurry shield TBMs.

Existing studies have largely focused on Earth pressure balance TBM tunneling; however, research on mud cake formation in a slurry shield TBM and its mitigation measure is limited. Dispersant molecules can effectively reduce the stickiness of clay minerals, indicating that the potential of mud cake formation can be decreased by mixing the excavated clay with a dispersant. However, the extent to which the dispersant can affect clay stickiness and mud cake formation has not yet been clarified.

In this study, dispersant was added to the slurry to reduce mud cake formation. The rheology, stability, and permeability of the filter cakes during their formation were determined to ensure that the slurry with a dispersant can meet the requirements for a support fluid in slurry shield TBM tunneling. Then, the empirical stickiness ratio was investigated using the mixing test proposed by Zumsteg and Puzrin [9] to evaluate the effects of the dispersant on mud cake formation. Finally, the viscosity of the suspension formed by mixing the slurry and excavated clay was measured. The findings of this study provide a reference for preventing mud cake formation in slurry shield TBM tunneling.

\section{Materials and Methods}

\subsection{Material}

2.1.1. Slurry Preparation. In this study, Na-bentonite and dispersant were used to prepare the slurry. The Na-bentonite was produced by Feilaifeng Nonmetal Mineral Material Co., Ltd. (Changde, Hunan, China). The bentonite had a moisture content of less than $13 \%$, a $75 \mu \mathrm{m}$ sieve residue of less than $2.5 \%$, and a pulping rate of more than $9 \%$. The dispersant is BASF Sokalan PA25 CL-FR dispersant, which is an anionic copolymer sodium salt.

The bentonite slurry was made with a Na-bentonite concentration of $8 \%$, which is commonly used in slurry shield TBMs. The remaining content was water and the dispersant. Five concentrations of the dispersant were used in the slurry: $0 \%, 4 \%, 6 \%, 8 \%$, and $10 \%$. The remaining content of the slurries was water. In this study, a slurry with a dispersant concentration of $2 \%$ was not used in the experiments because it was found to be prone to particle precipitation after preparation.

In the preparation of slurries with a dispersant, the bentonite was poured into water and then mixed for $12 \mathrm{~h}$; then, the dispersant was mixed in the slurry. The entire preparation process lasted for $24 \mathrm{~h}$ until the bentonite had sufficiently hydrated.

2.1.2. Clay Preparation. The clay used in the experiments was taken from the TBM tunnel of Wuhan Metro Line 8; its liquid limit, plastic limit, natural moisture content, plasticity index, and consistency index are 42.8\%, 26.6\%, 30.2\%, $16.2 \%$, and 0.778 , respectively. According to Thewes' method, the clay sample has a medium potential for mud cake formation at its natural moisture content, as shown in Figure 1 [3].

After the clay sample was dried, water was added to reach the natural moisture content state, after which the clay specimen remained undisturbed for $24 \mathrm{~h}$. The artificial clay lumps were produced by consolidating the clay samples in an oedometer cell to a final consolidation pressure of $500 \mathrm{kPa}$. The consolidated clay block was then cut into cubes of approximately $1 \mathrm{~cm}^{3}$ each, as shown in Figure 2 .

\subsection{Experimental Methods}

2.2.1. Overall Experimental Process. Two types of experiments were conducted in this study to determine the effects of the dispersant on the slurry's basic properties and mud cakes.

First, the slurry with dispersant should meet the requirements of a support liquid during slurry shield TBM tunneling. When a tunnel is being bored, the slurry needs to quickly form a dense filter cake under pressure in front of the cutter head. The amount of water seepage that occurs during the filter cake formation is an important factor for evaluating the filter cake densification. The short-term downtime for the erection of the slurry shield TBM segment, including equipment maintenance, is approximately $2 \mathrm{~h}$, and when tunnel face support pressure is used, the working time for hyperbaric intervention is approximately $24 \mathrm{~h}$ [15]. Therefore, it was necessary to measure the slurry segregation ratio at $2 \mathrm{~h}$ and $24 \mathrm{~h}$. In addition, the slurry viscosity $(\eta)$ is an important indicator of slurry performance. Therefore, a series of tests were performed to determine the slurry 


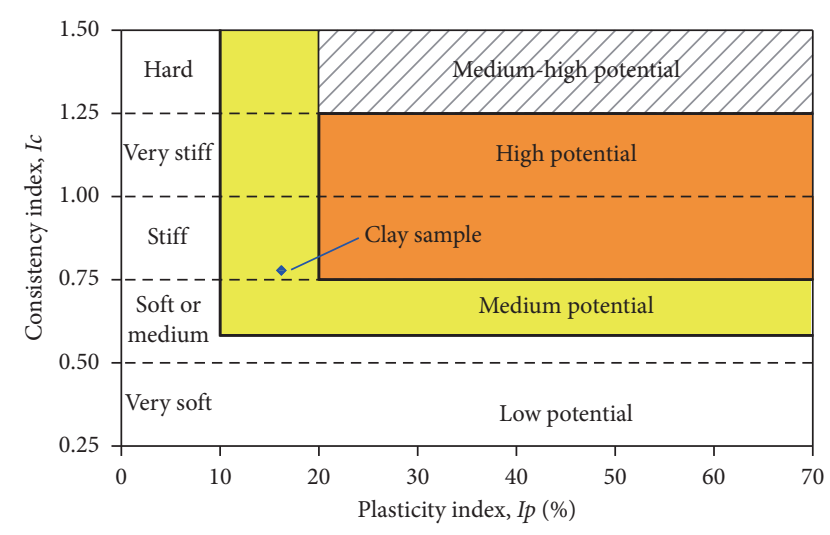

Figure 1: Modified clogging potential based on Thewes' method [3].

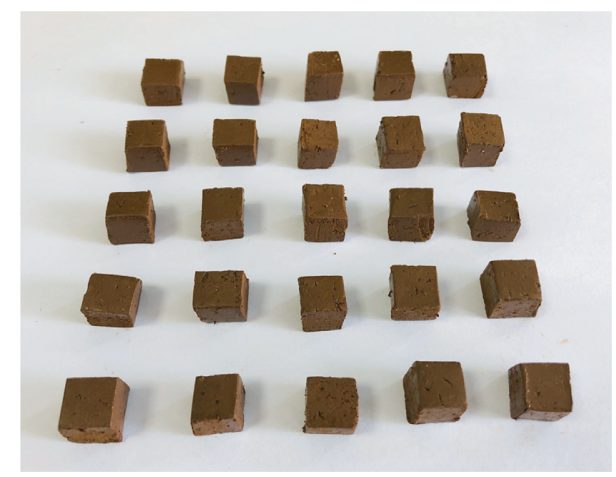

Figure 2: Artificial clay lumps.

properties, including investigating the rheology, stability, and permeability of the filter cakes during their formation.

Second, the effectiveness of the dispersant for reducing mud cakes was investigated by determining the empirical stickiness ratio and suspension viscosity. The mixing test simulated a TBM-like rotational shearing of the clay at the contact interfaces with steel surfaces using an empirical stickiness ratio, $\lambda$. This simple procedure has been previously applied to quantify the beneficial (i.e., stickiness reduction) effects of soil conditioners [12]. The suspension was formed by mixing the slurry and the excavated clay, and its specific gravity was expressed by $\gamma$. The viscosity of a suspension is an important index to measure the stickiness of the mixture (mixture of excavated clay and slurry) and evaluate the risk of mud cake formation. Therefore, the viscosity of the suspension $(\eta)$ was also measured. The effects of the dispersant on mud cakes were then analyzed using the empirical stickiness ratio and suspension viscosity data.

Three runs were performed for each test scenario, and the average value was used as the final result. If the difference between the three test results did not exceed $10 \%$ of the intermediate value, the results were considered acceptable. Otherwise, the experiments were repeated.

\subsubsection{Slurry Properties Test}

(1) Rheology Test. The slurry rheology test measured the variation in the slurry viscosity at $25^{\circ} \mathrm{C}$. An NDJ-9T digital rotary viscometer was used to measure the viscosity, and a thermostatic water bath maintained a constant temperature. These two devices were produced by Shanghai Jitai Electronic Technology Co. Ltd., China.

(2) Stability Test. The stability test measured the segregation ratio, which is the ratio of the volume of water separated from the slurry to the total slurry volume in $24 \mathrm{~h}$. In this study, $200 \mathrm{ml}$ of the prepared slurry was poured into a $250 \mathrm{ml}$ cylinder, and the portion of water that was segregated in $24 \mathrm{~h}$ was measured.

(3) Permeability Test. The permeability coefficient is an important index for evaluating filter cakes and is related to the ratio of the conversion of support stress (effective stress) of the filter cake. This test measured the amount of liquid seepage discharged in $30 \mathrm{~min}$ during filter cake formation at 0.4 MPa. A ZNS-2A slurry filter (Qingdao Jiaonan Analytical Instrument Factory, China) was used in this test, and the slurry cup filtration area is $45.6 \mathrm{~cm}^{2}$. An electronic scale was placed under the slurry cup and connected to a laptop to record the real-time seepage discharged from the slurry cup, as shown in Figure 3. The test procedures are as follows:

(i) We poured $150 \mathrm{~g}$ slurry into the slurry cup, an O-ring and a wet filter paper were placed on top of the slurry, and the cap of the slurry cup was tightened. The slurry cup was then connected to the air inlet.

(ii) The pressure was increased to $0.4 \mathrm{MPa}$, and the mass of water accumulated from when the air valve was opened until the end of the test was measured.

\subsubsection{Reduction Analysis of Mud Cakes}

(1) Mixing Test. The mixing test proposed by Zumsteg and Puzrin [9] was adopted to determine the empirical stickiness ratio, $\lambda$, which is the ratio of the mass of clay sticking to the beater $\left(G_{M T}\right)$ to the total mass of clay in the mixer $\left(G_{T O T}\right)$, as given in equation (1).

$$
\lambda=\frac{G_{M T}}{G_{\mathrm{TOT}}} .
$$

The test was conducted using an NJ-160B mortar mixer (as shown in Figure 4) as follows:

(i) The beater was weighed and installed in the mixer

(ii) Previously prepared clay lumps were placed in a mixing bowl, followed by a moderate amount of slurry

(iii) The mixer was started, and the clay and slurry were mixed for $2 \mathrm{~min}$ at low speed

(iv) The beater was removed and weighed to obtain the empirical stickiness ratio

In slurry shield TBM tunneling, the specific gravity, $\gamma$, of the suspension is typically controlled within the range of $1.25-1.40 \mathrm{~g} / \mathrm{cm}^{3}$ in clay stratum. Therefore, in this test, $\gamma$ was controlled to be $1.25 \mathrm{~g} / \mathrm{cm}^{3}, 1.30 \mathrm{~g} / \mathrm{cm}^{3}, 1.35 \mathrm{~g} / \mathrm{cm}^{3}$, and $1.40 \mathrm{~g} / \mathrm{cm}^{3}$ by adjusting the ratio of the clay lumps to the slurry. After mixing at a low speed for $2 \mathrm{~min}, \lambda$ of the pure 


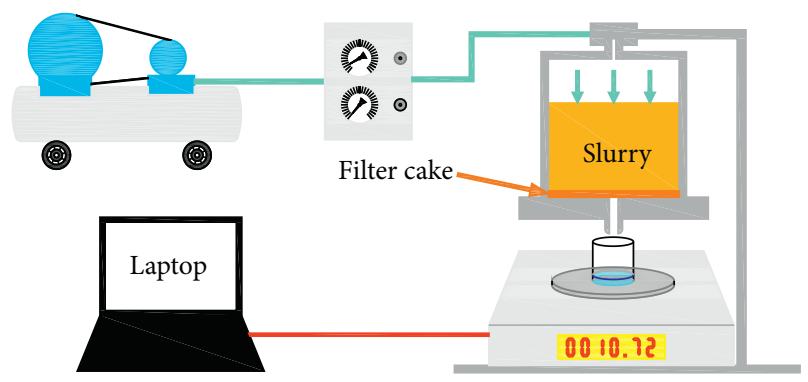

(a)

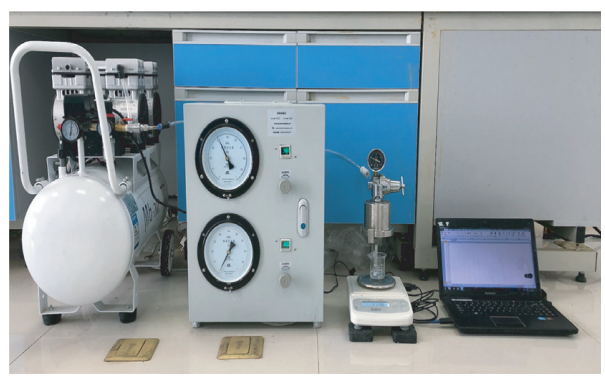

(b)

Figure 3: Permeability measurement system: (a) schematic diagram; (b) experimental setup.

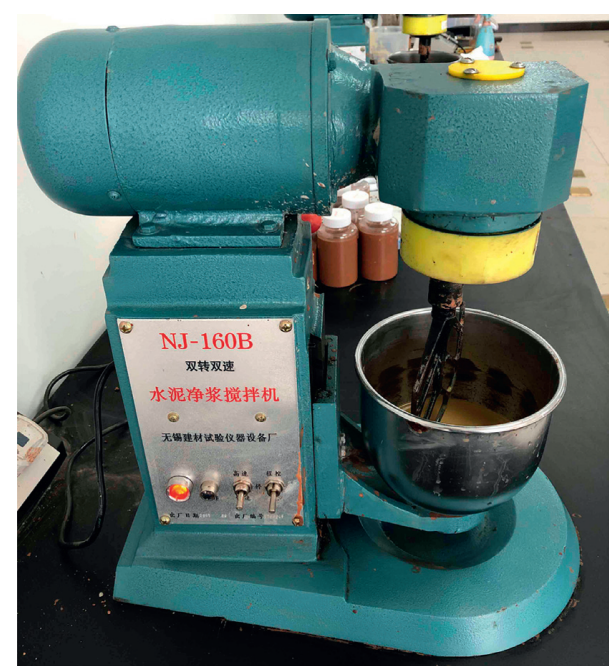

FIgURE 4: NJ-160 B mortar mixer.

bentonite slurry and slurries with dispersant contents of $4 \%$, $6 \%, 8 \%$, and $10 \%$ were measured at different $\gamma$ values.

(2) Suspension Viscosity. After measuring the $\lambda$ values, the clay on the beater was scraped into the mixing bowl and mixed at a low speed until a stable suspension was formed. The suspension viscosity was then measured using the NDJ-9T rotary viscometer at $25^{\circ} \mathrm{C}$. The equipment used in this testing was the same as that used for the rheology test (Section 2.2.2).

\section{Results}

\subsection{Basic Slurry Properties}

3.1.1. Rheological Properties of Slurries. The viscosities of the slurry samples are illustrated in Figure 5, which shows that both slurry types demonstrated shear thinning characteristics. At a low shear rate, the rheological properties of a slurry can be described by a pseudoplastic fluid model. Further, a dispersant does not change the basic rheological properties of the slurry, while significantly reducing its viscosity. The slurry with $4 \%$ dispersant had the lowest viscosity. As the concentration of the dispersant increased, the viscosity of the slurry also increased but remained

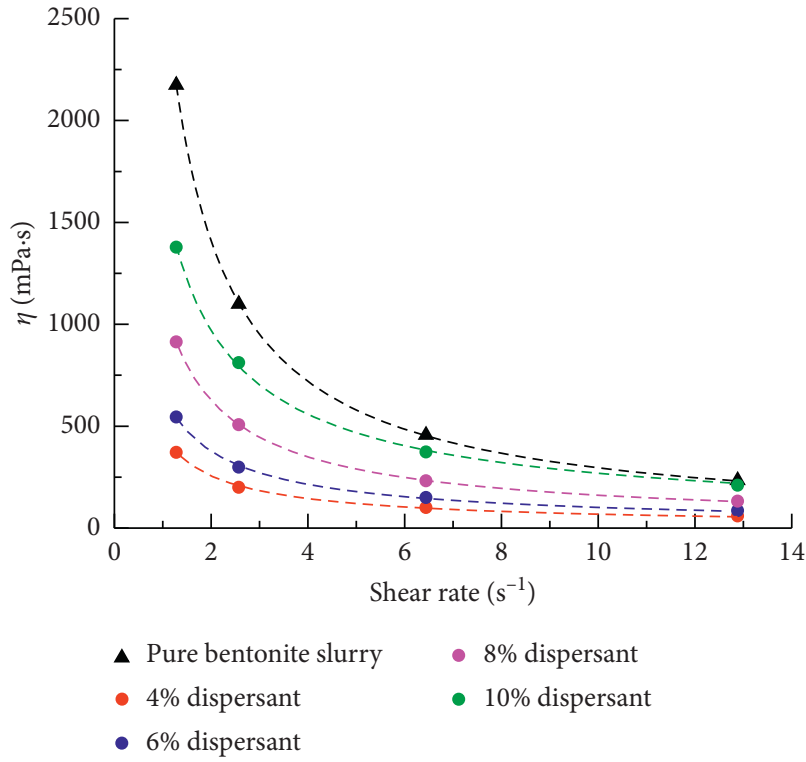

FIgURe 5: Slurry viscosity measurements.

lower than the viscosity of the pure bentonite slurry in all cases.

3.1.2. Slurry Stability. The segregation ratios of the slurries at $2 \mathrm{~h}$ and $24 \mathrm{~h}$ are reported in Table 1 . The variation in the slurry stability during a $24 \mathrm{~h}$ test is shown in Figure 6. No segregation occurred in any of the slurries within the first $2 \mathrm{~h}$, and the segregation ratio of the pure bentonite slurry remained at 0 after $24 \mathrm{~h}$. For slurries with a dispersant, the segregation ratios gradually decreased as the dispersant concentration increased and increased over time. Between $2 \mathrm{~h}$ and $12 \mathrm{~h}$, the segregation ratio increased gradually but then slowed and was almost constant between $12 \mathrm{~h}$ and $24 \mathrm{~h}$. The slurry with $4 \%$ dispersant had the highest final segregation ratio of $1.6 \%$ at $24 \mathrm{~h}$. The segregation ratios of slurries with the other dispersant concentrations were $1 \%$ or less, which is considered to be very low. Therefore, slurries with a dispersant satisfied the stability requirements.

3.1.3. Permeability during Filter Cake Formation. The variation in the permeability of the filter cakes within the first 
TABLE 1: Slurry properties.

\begin{tabular}{|c|c|c|c|c|}
\hline \multirow{2}{*}{ Slurry } & \multicolumn{2}{|c|}{ Seepage discharge (g) } & \multicolumn{2}{|c|}{ Segregation ratio (\%) } \\
\hline & $60 \mathrm{~s}$ & $30 \mathrm{~min}$ & $2 \mathrm{~h}$ & $24 \mathrm{~h}$ \\
\hline Pure bentonite slurry & 2.34 & 14.05 & 0.00 & 0.00 \\
\hline Slurry with $4 \%$ dispersant & 1.17 & 7.27 & 0.00 & 1.60 \\
\hline Slurry with $6 \%$ dispersant & 1.23 & 7.58 & 0.00 & 1.00 \\
\hline Slurry with $8 \%$ dispersant & 1.38 & 8.84 & 0.00 & 0.96 \\
\hline Slurry with $10 \%$ dispersant & 1.58 & 9.82 & 0.00 & 0.88 \\
\hline
\end{tabular}

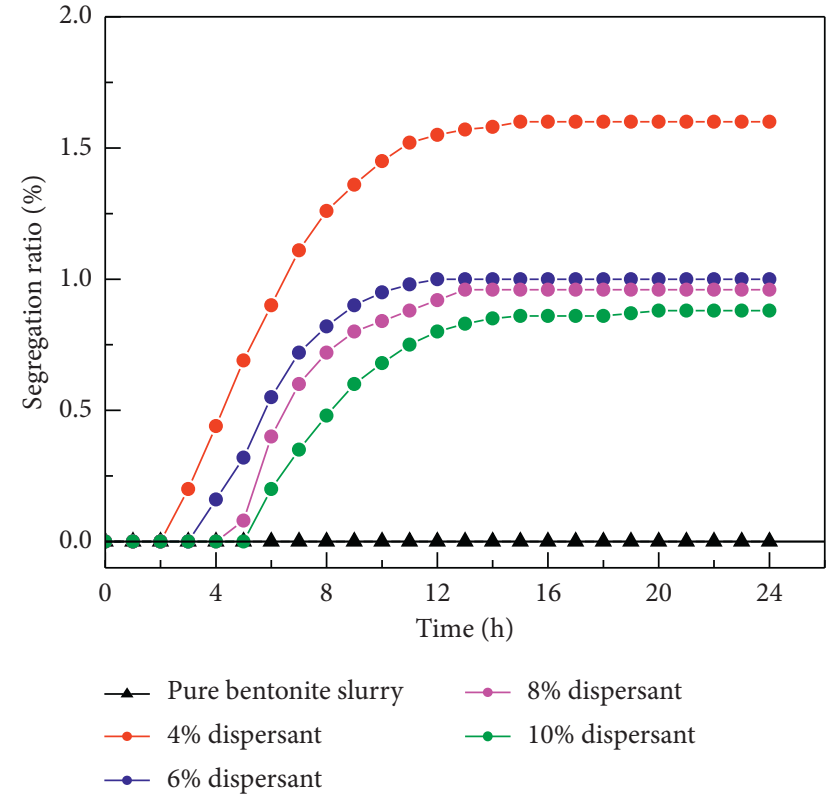

Figure 6: Segregation ratios.

$60 \mathrm{~s}$ and $30 \mathrm{~min}$ during the formation of filter cakes while the slurries were under a pressure of $0.4 \mathrm{MPa}$ is shown in Figure 7; Table 1 provides the seepage discharge values. The curves illustrate that the addition of a dispersant significantly reduced seepage discharge during filter cake formation.

The seepage discharge of slurries with dispersant concentrations of $4 \%, 6 \%, 8 \%$, and $10 \%$ at $30 \mathrm{~min}$ were, respectively, $48.26 \%, 46.05 \%, 37.08 \%$, and $30.11 \%$ less than that of the pure bentonite slurry, as shown in Figure 7(b). The seepage discharge gradually increased with an increase in the dispersant concentration but was always lower than that of the pure bentonite slurry. The first $60 \mathrm{~s}$ of filter cake formation demonstrated the same trends.

\subsection{Determining the Reduction of Mud Cakes}

3.2.1. Empirical Stickiness Ratio. Figure 8 shows the variation in $\lambda$ for different values of $\gamma$ as a function of the dispersant concentration. The dispersant effectively reduced the $\lambda$ values, particularly at $\gamma=1.30-1.40 \mathrm{~g} / \mathrm{cm}^{3}$; for $\gamma$ values of $1.25 \mathrm{~g} / \mathrm{cm}^{3}$ and $1.30 \mathrm{~g} / \mathrm{cm}^{3}$, the $\lambda$ values gradually decreased as the dispersant concentration increased, but the magnitude of the decrease was less sensitive to changes in the dispersant concentration and $\gamma$. However, at $\gamma=1.35 \mathrm{~g} / \mathrm{cm}^{3}$ and $1.40 \mathrm{~g} /$ $\mathrm{cm}^{3}, \lambda$ followed a distinctly different trend, as shown in
Figure 9. It first decreased and then increased as the dispersant concentration increased. For slurries with a dispersant, $\lambda$ was always lower than that for the pure bentonite slurry.

For the pure bentonite slurry, $\lambda$ substantially increased from $5.24 \%$ to $37.23 \%$ when $\gamma$ increased from $1.25 \mathrm{~g} / \mathrm{cm}^{3}$ to $1.40 \mathrm{~g} / \mathrm{cm}^{3}$ (see Figure 8). The relationship between $\lambda$ and $\gamma$ was analyzed for slurries with a dispersant, as shown in Figure 10 . In general, $\lambda$ was approximately positively related to $\gamma$, and its increased magnitude was approximately positively related to $\gamma$ for each dispersant concentration. The $\lambda$ value of slurries with $4 \%$ dispersant was the highest at each $\gamma$. For slurries with dispersant concentrations of $6 \%, 8 \%$, and $10 \%$, the growth rate of $\lambda$ with respect to $\gamma$ increased with increasing dispersant concentration.

3.2.2. Suspension Viscosity. The variation in the viscosity of the suspension, $\eta$, as a function of the dispersant concentration is shown in Figure 11. The results were measured at $25^{\circ} \mathrm{C}$ and at a shear rate of $12.88 \mathrm{~s}^{-1}$. For the pure bentonite slurry samples, $\eta$ increased with $\gamma$, and the values were high, ranging from $1200 \mathrm{mPa} \cdot \mathrm{s}$ to $1500 \mathrm{mPa}$. The values of $\eta$ for slurries with a dispersant were generally low, with a maximum value of $890 \mathrm{mPa}$.s. For $\gamma$ values of $1.25 \mathrm{~g} / \mathrm{cm}^{3}$ and $1.30 \mathrm{~g} / \mathrm{cm}^{3}$, the $\eta$ values gradually increased as the dispersant concentration increased, but the magnitude of the increase was less sensitive to changes in $\gamma$. However, at $\gamma=1.35 \mathrm{~g} / \mathrm{cm}^{3}$ and $1.40 \mathrm{~g} / \mathrm{cm}^{3}, \eta$ followed a distinctly different trend, as shown in Figure 11. It first decreased and then increased as the dispersant concentration increased.

\section{Discussion}

4.1. Mechanisms of Dispersant Effects on Slurry Properties. As shown in Figure 12, Na-bentonite peels off as very thin flakes after hydrolysis. The interaction between the surface charge and the edge charge of the flakes then causes a gel reaction. Eventually, microstructures are formed, which have a larger volume than the flakes. A dispersant increases the overall negative surface charge on the flakes to which it becomes attached, reducing the tendency of the flakes to flocculate as a result of the variable distribution of charge on the particles, thereby maintaining a lower viscosity dispersed state [16-21].

Compared with the microstructures formed by the gel reaction of a pure bentonite slurry, the smaller bentonite flakes of a slurry with a dispersant can quickly form a denser filter cake on the surface of the filter paper, which explains 


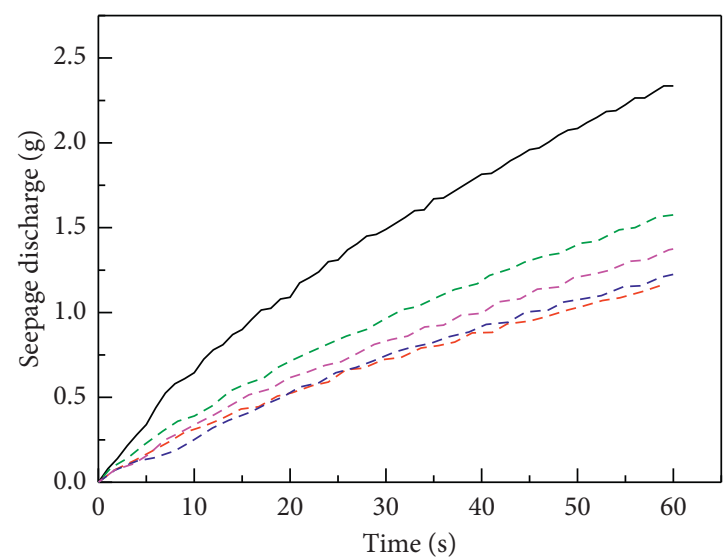

- Pure bentonite slurry $---8 \%$ dispersant
$---4 \%$ dispersant
$---6 \%$ dispersant

(a)

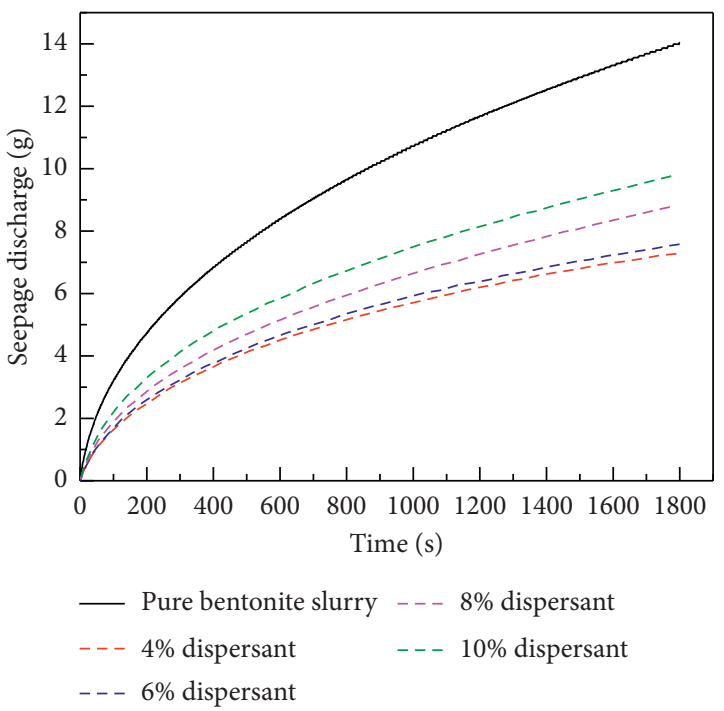

(b)

Figure 7: Seepage discharge during filter cake formation after (a) $60 \mathrm{~s}$ and (b) $30 \mathrm{~min}$.

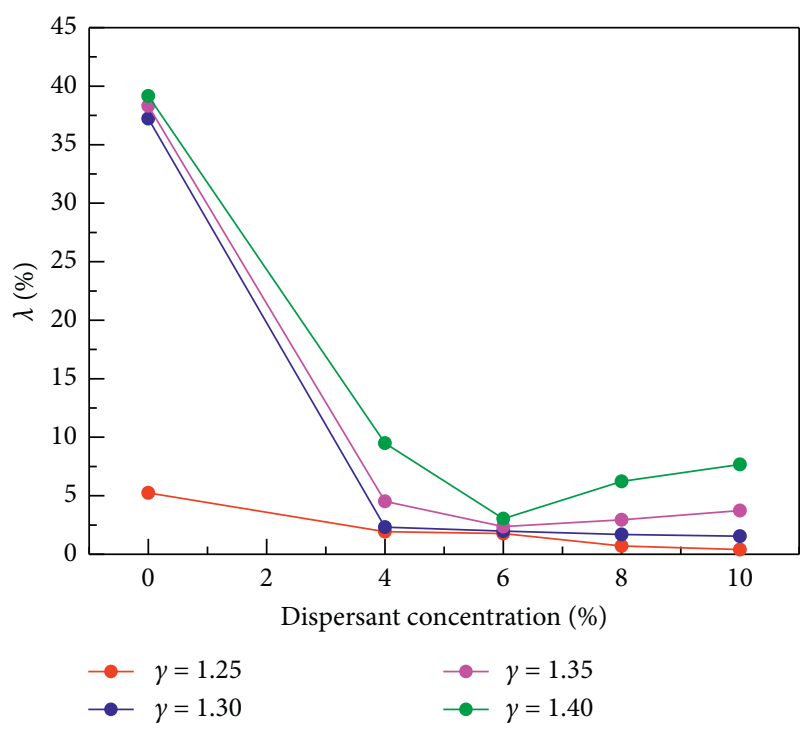

FIGURE 8: Effect of dispersant concentration on the empirical stickiness ratio, $\lambda$.

why lower viscosity slurries with a dispersant produced less seepage discharge during filter cake formation.

\subsection{Effect of Dispersant on Mud Cake Formation}

4.2.1. Empirical Stickiness Ratio and Mud Cake Formation. According to Zumsteg [10], the mixture (mixed with clay and slurry) could be considered to have a low potential of mud cake formation when its $\lambda$ is less than $20 \%$. The addition of a dispersant during the mixing test ensured that $\lambda$ was significantly lower than $20 \%$. The dispersant can effectively prevent the formation of mud cakes in the light of the experimental results.
For further analysis of the effects of the dispersant, two coefficients, the dispersant mass ratio $\left(\alpha_{d}\right)$ and the water mass ratio $\left(\alpha_{w}\right)$, were proposed, which represent the ratios of the masses of the dispersant $\left(m_{d}\right)$ and water $\left(m_{w}\right)$ to the mass of clay $\left(m_{s}\right)$, as given in equations (2) and (3).

$$
\begin{gathered}
\alpha_{d}=\frac{m_{d}}{m_{s}}, \\
\alpha_{w}=\frac{m_{w}}{m_{s}} .
\end{gathered}
$$

Given the empirical nature of $\lambda$, it is important to explore if it can correlate with $\alpha_{d}$. The relationship between $\lambda$ and $\alpha_{d}$ of the mixtures is shown in Figure 13.

At lower values of $\alpha_{d}, \lambda$ was significantly affected by the dispersant, but the sensitivity of $\lambda$ to variations in $\alpha_{d}$ gradually decreased with the increase in $\alpha_{d}$. That is, for the same dispersant concentration, $\alpha_{d}$ gradually decreased with the increase in $\gamma$, causing $\lambda$ to become increasingly sensitive to changes in $\gamma$. The above analysis is consistent with the plot in Figure 10.

At low $\gamma$ values $\left(1.25 \mathrm{~g} / \mathrm{cm}^{3}\right.$ or $\left.1.30 \mathrm{~g} / \mathrm{cm}^{3}\right)$, the content of the dispersant and water was sufficient, and the sensitivity of $\lambda$ to changes in $\alpha_{d}$ gradually decreased. Therefore, the $\lambda$ values gradually decreased as the dispersant concentration increased; however, the magnitude of the decrease was less sensitive to changes in the concentration and $\gamma$, as shown in Figure 8.

At high $\gamma$ values $\left(1.35 \mathrm{~g} / \mathrm{cm}^{3}\right.$ or $\left.1.40 \mathrm{~g} / \mathrm{cm}^{3}\right)$, the sum of $\alpha_{d}$ and $\alpha_{w}$ was less than that at low $\gamma$ values. At a lower dispersant concentration, the dispersant was insufficient to control the stickiness of the clay, which resulted in higher values of $\lambda$ as indicated by the wine red circle in Figure 13. This is the reason why the value of $\lambda$ was the highest when the slurry with $4 \%$ dispersant was used to prepare the suspension with $\gamma=1.40 \mathrm{~g} / \mathrm{cm}^{3}$ (see Figure 8). With the increase in the dispersant concentration, the 


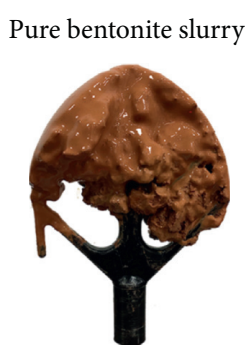

(a)

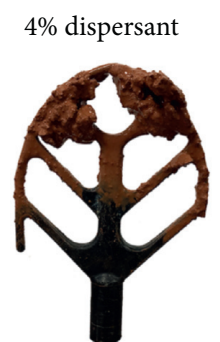

(b)

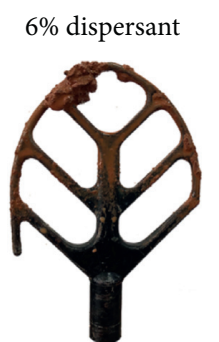

(c)

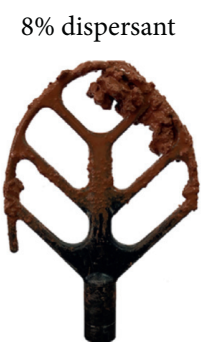

(d)

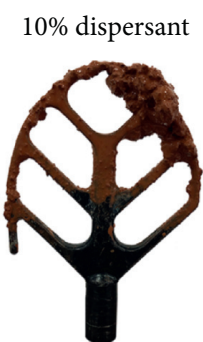

(e)

Figure 9: Clay sticking to the beater at $\gamma=1.40 \mathrm{~g} / \mathrm{cm}^{3}$.

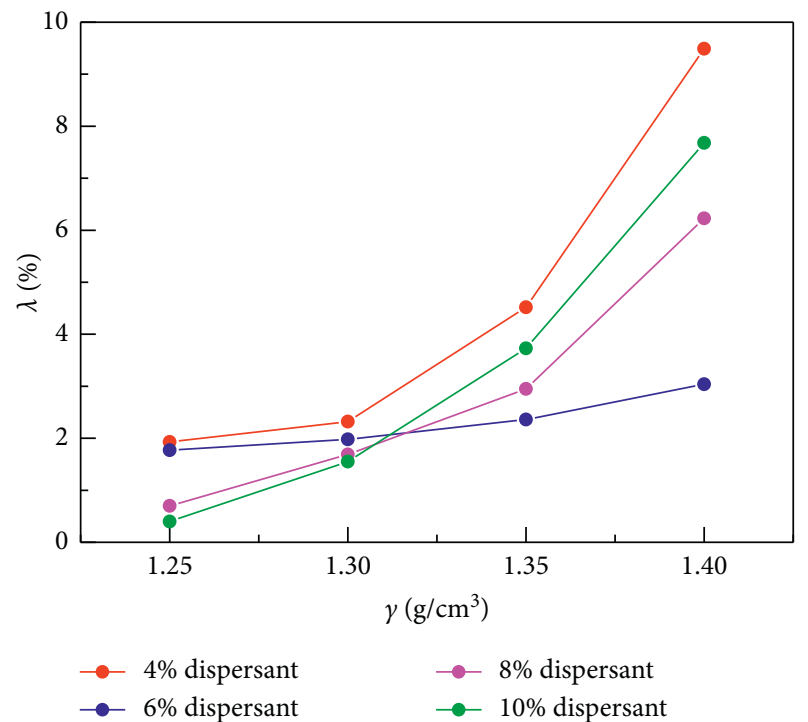

FIgURe 10: Effect of specific gravity on the empirical stickiness ratio.

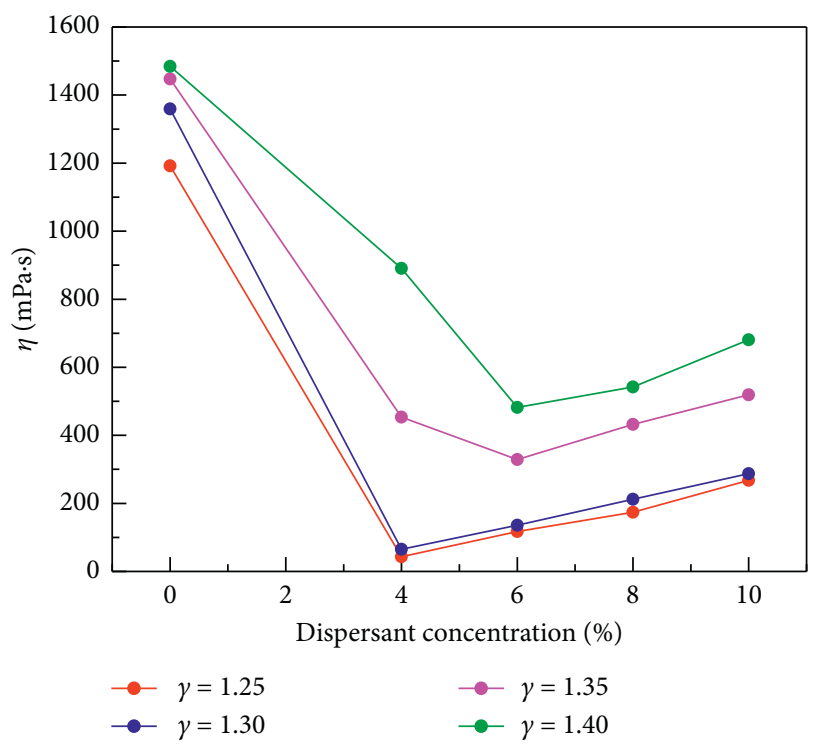

FIGURE 11: Relationship between the viscosity of the suspension and dispersant concentration.

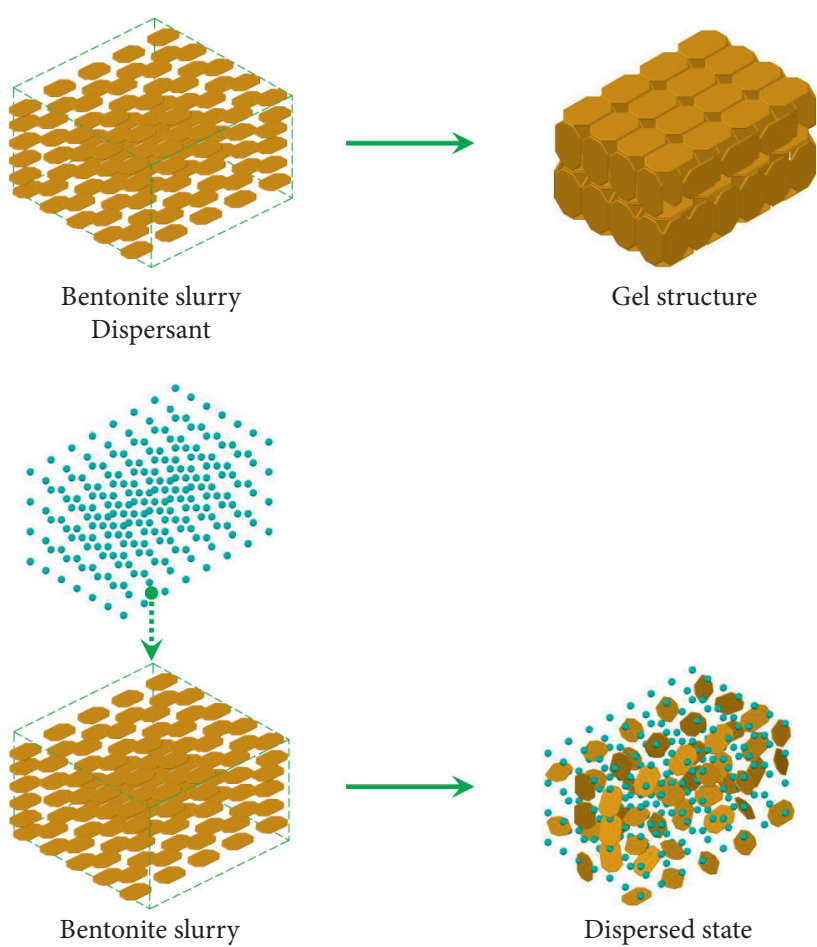

Figure 12: Dispersant mechanisms of action.

content of the dispersant and water reached the optimal value first, and then the water content was insufficient, leading to high values of $\lambda$ as indicated by the green circle in Figure 13. Therefore, the $\lambda$ values first decreased and then increased as the dispersant concentration increased (see Figure 8).

The addition of a dispersant effectively reduced the risk of mud cakes, but the sensitivity of the risk reduction to changes in the dispersant content gradually decreased with the increase in the dispersant content. The formation of mud cakes was also affected by the water content of the mixture to a certain extent, particularly at high $\gamma$ values. This indicates that there are optimal values for the content of the dispersant in practical use. The optimal values of the dispersant concentration from the mixing tests are marked with a grey circle in Figure 13, which are $4 \%$ for low $\gamma$ values $\left(1.25 \mathrm{~g} / \mathrm{cm}^{3}\right.$ or $\left.1.30 \mathrm{~g} / \mathrm{cm}^{3}\right)$ and $6 \%$ for high $\gamma$ values $\left(1.35 \mathrm{~g} / \mathrm{cm}^{3}\right.$ or $1.40 \mathrm{~g} /$ $\mathrm{cm}^{3}$ ). 


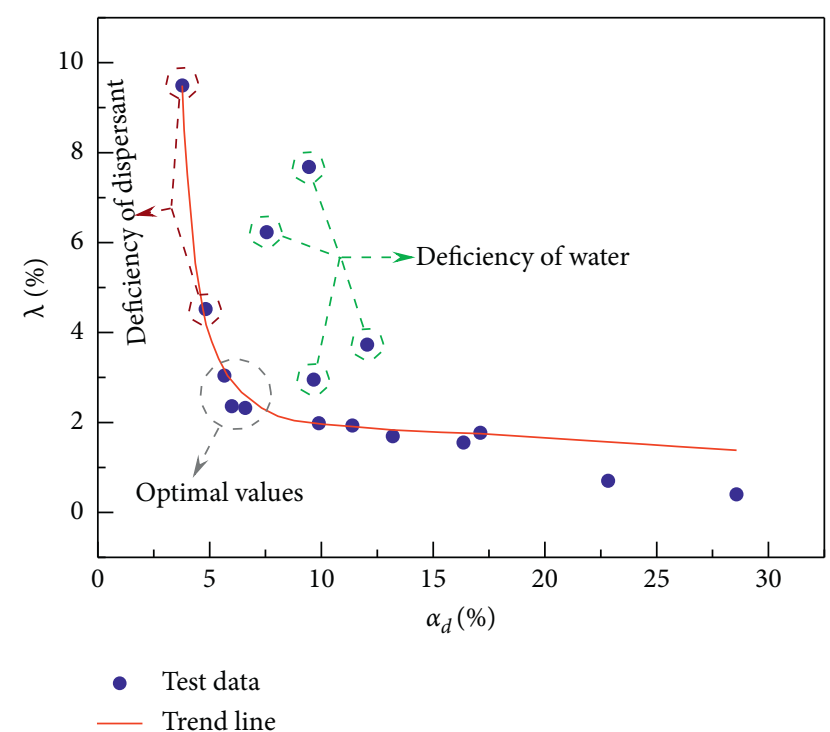

FIGURE 13: Correlation between the empirical stickiness ratio and dispersant mass ratio.

4.2.2. Suspension Viscosity and Mud Cake Formation. As proposed in a previous study [22], an absorbed water film of clay particles forms after the suspension of pure bentonite slurry was generated, as illustrated in Figure 14. These clay particles then interact with the adsorbed water film, attract each other, and agglomerate. After the dispersant molecules interact with the clay particles, the thickness of the water film around the clay particles increases, significantly reducing or even eliminating the attraction between the particles. The clay particles disperse in turn more uniformly, significantly reducing the viscosity, as shown in Figure 11. Compared with agglomerations, the dispersed clay particles are less likely to form mud cakes on the cutter head of a slurry shield TBM.

Linear regression was performed on the $\eta$ values of the suspensions with respect to $\alpha_{d}$, and two outliers of the test data marked with a wine red circle in Figure 15 were eliminated. The relationship between $\eta$ and $\alpha_{d}$ is shown in Figure 15.

Overall, $\eta$ was positively related to $\alpha_{d}$ for each $\gamma$, and the slope of the regression line increased with the increase in the value of $\gamma$. The increase of dispersant content should be cautious at high $\gamma$ values. The two outliers of the test data in Figure 15 resulted from the deficiency of the dispersant content, similar to the description in Section 4.2.1. Both the dispersant and water affected the $\eta$ values of the suspension similar to $\lambda$, and the addition of the dispersant was found to effectively reduce the $\eta$ values of the suspension.

However, when $\gamma$ was $1.25 \mathrm{~g} / \mathrm{cm}^{3}$ or $1.30 \mathrm{~g} / \mathrm{cm}^{3}$, the content of the dispersant and water was sufficient. The $\eta$ values of the suspension increased with the increase in the dispersant content for high $\eta$ of the dispersant. When $\gamma$ was $1.35 \mathrm{~g} / \mathrm{cm}^{3}$ or $1.40 \mathrm{~g} / \mathrm{cm}^{3}$, the dispersant of $4 \%$ concentration was insufficient to control the stickiness of clay, which resulted in high $\eta$ values of the suspension. With the increase in the dispersant content, the contents of the dispersant and water reached their optimal values first, then the water

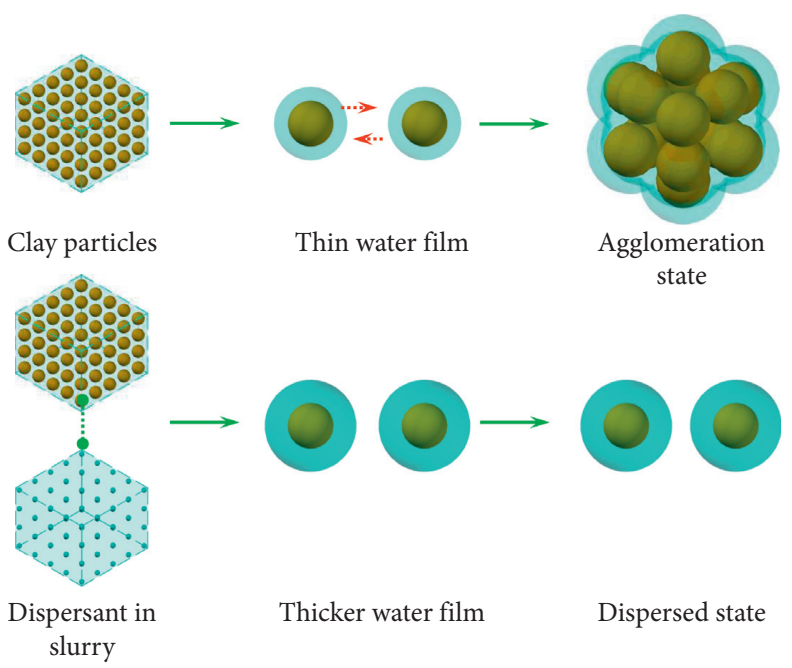

FIgURE 14: Mechanism of dispersant effects on clay particles.

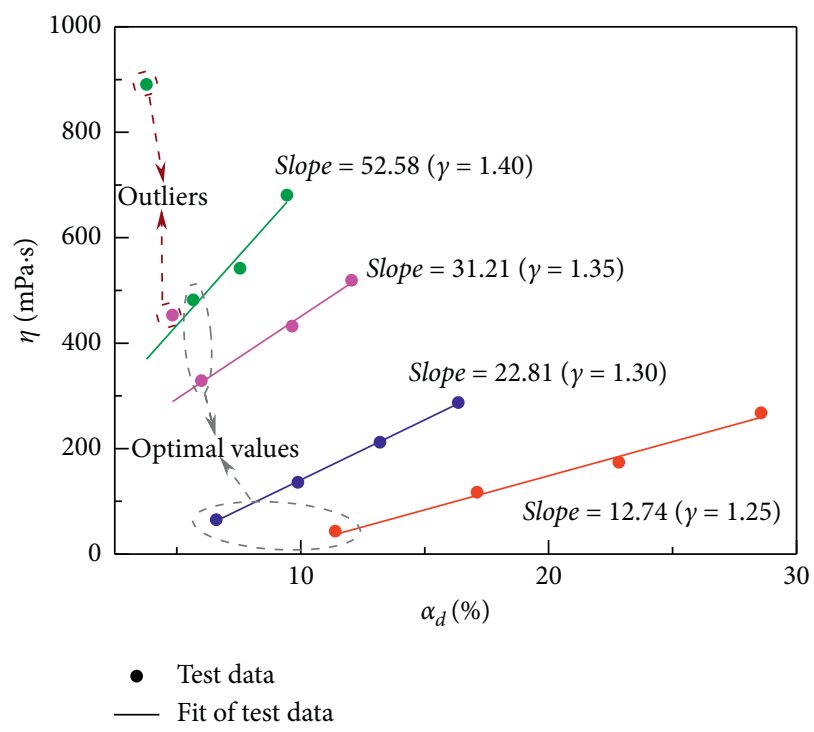

FIGURE 15: Regression of the viscosity with respect to the mass ratios of the dispersant.

content was insufficient. Therefore, the $\eta$ values of the suspension first decreased and then increased as the dispersant concentration increased.

The $\eta$ of the suspension is an important index to evaluate the stickiness of the mixture (mixture of slurry and clay). The smaller the $\eta$, the smaller the impact on the formation of mud cakes. The optimal values of the dispersant concentration from the suspension viscosity test are indicated with a grey circle in Figure 15, which are $4 \%$ for low $\gamma$ values $\left(1.25 \mathrm{~g} / \mathrm{cm}^{3}\right.$ or $\left.1.30 \mathrm{~g} / \mathrm{cm}^{3}\right)$ and $6 \%$ for high $\gamma$ values $(1.35 \mathrm{~g} /$ $\mathrm{cm}^{3}$ or $\left.1.40 \mathrm{~g} / \mathrm{cm}^{3}\right)$.

Therefore, for the clay used in this study, the optimal values of the dispersant concentration were $4 \%(\gamma \leq 1.30 \mathrm{~g} /$ $\left.\mathrm{cm}^{3}\right)$ and $6 \%\left(\gamma>1.30 \mathrm{~g} / \mathrm{cm}^{3}\right)$ for different specific suspension gravities $\left(1.25-1.40 \mathrm{~g} / \mathrm{cm}^{3}\right)$ during the tunneling process of a slurry shield TBM. 


\section{Conclusions}

Mud cakes occur when a slurry shield TBM encounters clay soil. In this study, the effects of a dispersant on the basic properties of slurries and the potential for mud cake formation were investigated experimentally. The following conclusions were drawn based on the results and analyses:

(1) The dispersant proposed in this study could effectively reduce the risk of mud cake formation without negatively affecting the basic properties of slurries. It can be used as a slurry additive for a slurry shield TBM in the sticky ground.

(2) The slurry with a dispersant demonstrated fundamental properties that were superior to those of the pure bentonite slurry. The addition of a dispersant significantly reduced the slurry viscosity without changing the rheologic properties of the typical bentonite slurry. Slurries with a dispersant more quickly formed a dense and effective filter cake; although its stability was somewhat poor, this would not impact TBM operations. Therefore, the slurry with a dispersant could fully satisfy the requirements for use in slurry shield TBM tunneling.

(3) The dispersant effectively reduced the empirical stickiness ratio of clay and the viscosity of the suspension. The required dispersant concentration was different for different $\gamma$ values of the suspension. For the clay used in this study, when $\gamma$ was not higher than $1.30 \mathrm{~g} / \mathrm{cm}^{3}$, the optimal value of the dispersant concentration was $4 \%$, whereas the optimal concentration when $\gamma$ was between $1.30 \mathrm{~g} / \mathrm{cm}^{3}$ and $1.40 \mathrm{~g} / \mathrm{cm}^{3}$ was $6 \%$.

\section{Data Availability}

All data generated or analyzed during this study are included in this article.

\section{Conflicts of Interest}

The authors declare that they have no conflicts of interest.

\section{Acknowledgments}

This work was financially supported by the National Natural Science Foundation of China (nos. 51879150 and 41831278).

\section{References}

[1] P. Fritz, "Additives for slurry shields in highly permeable ground," Rock Mechanics and Rock Engineering, vol. 40, pp. 81-95, 2007.

[2] Y.-M. Ryu, Y.-S. Kwon, T.-H. Kim, and I.-M. Lee, "Slurry clogging criteria for slurry shield tunnelling in highly permeable ground," KSCE Journal of Civil Engineering, vol. 23, no. 6, pp. 2784-2793, 2019.

[3] M. Thewes, Adhäsion von tonböden beim tunnelvortrieb mit flüssigkeitsschilden, Bergische Universität Gesamthochschule, Wuppertal, Germany, 1999.
[4] I. Sass and U. Burbaum, "A method for assessing adhesion of clays to tunneling machines," Bulletin of Engineering Geology and the Environment, vol. 68, pp. 27-34, 2009.

[5] M. Thewes and W. Burger, "Clogging of TBM drives in clay identification and mitigation of risks, undergr. Sp. Use anal. Past lessons futur. - proc. 31st ITA-AITES world tunn," Congr, vol. 2, pp. 737-742, 2005.

[6] F. S. Hollmann and M. Thewes, "Assessment method for clay clogging and disintegration of fines in mechanised tunnelling," Tunnelling and Underground Space Technology, vol. 37, pp. 96-106, 2013.

[7] M. Thewes and F. Hollmann, "Assessment of clay soils and clay-rich rock for clogging of TBMs," Tunnelling and Underground Space Technology, vol. 57, pp. 122-128, 2016.

[8] M. Feinendegen, M. Ziegler, G. Spagnoli, T. FernándezSteeger, and H. Stanjek, "A new laboratory test to evaluate the problem of clogging in mechanical tunnel driving with EPBshields," in Proceedings of the European Rock Mechanics Symposium (EUROCK) 2010, Lausanne, Switzerland, June 2010.

[9] R. Zumsteg and A. M. Puzrin, "Stickiness and adhesion of conditioned clay pastes," Tunnelling and Underground Space Technology, vol. 31, pp. 86-96, 2012.

[10] R. Zumsteg, M. Plotze, and A. Puzrin, "Reduction of the clogging potential of clays: new chemical applications and novel quantification approaches," Bio- and Chemo-Mechanical Processes in Geotechnical Engineering: Géotechnique Symposium in Print, pp. 44-54, 2013.

[11] D. Peila, A. Picchio, D. Martinelli, and E. D. Negro, "Laboratory tests on soil conditioning of clayey soil," Acta Geotechnica, vol. 11, no. 5, pp. 1061-1074, 2016.

[12] R. Zumsteg, A. M. Puzrin, and G. Anagnostou, "Effects of slurry on stickiness of excavated clays and clogging of equipment in fluid supported excavations," Tunnelling and Underground Space Technology, vol. 58, pp. 197-208, 2016.

[13] D. G. G. de Oliveira, M. Thewes, M. S. Diederichs, and L. Langmaack, "EPB tunnelling through clay-sand mixed soils: proposed methodology for clogging evaluation," Geomechanics and Tunnelling, vol. 11, no. 4, pp. 375-387, 2018.

[14] X. Vittorio, G. Piergiorgio, and M. Ashraf, Mechanized Tunnelling in Urban Areas, CRC Press, London, UK, 2008.

[15] F. Min, J. Du, N. Zhang et al., "Experimental study on property change of slurry and filter cake of slurry shield under seawater intrusion," Tunnelling and Underground Space Technology, vol. 88, pp. 290-299, 2019.

[16] G. Lagaly, "Principles of flow of kaolin and bentonite dispersions," Applied Clay Science, vol. 4, no. 2, pp. 105-123, 1989.

[17] T. Permien and G. Lagaly, "The rheological and colloidal properties of bentonite dispersions in the presence of organic compounds $\mathrm{V}$. bentonite and sodium montmorillonite and surfactants," Clays and Clay Minerals, vol. 43, no. 2, pp. 229-236, 1995.

[18] M. H. Baik and S. Y. Lee, "Colloidal stability of bentonite clay considering surface charge properties as a function of $\mathrm{pH}$ and ionic strength," Journal of Industrial and Engineering Chemistry, vol. 16, no. 5, pp. 837-841, 2010.

[19] R. Goh, Y.-K. Leong, and B. Lehane, "Bentonite slurries-zeta potential, yield stress, adsorbed additive and time-dependent behaviour," Rheologica Acta, vol. 50, no. 1, pp. 29-38, 2011.

[20] K. Y. Choo and K. Bai, "Effects of bentonite concentration and solution $\mathrm{pH}$ on the rheological properties and long-term stabilities of bentonite suspensions," Applied Clay Science, vol. 108, pp. 182-190, 2015. 
[21] W. Huang, Y.-K. Leong, T. Chen, P.-I. Au, X. Liu, and Z. Qiu, "Surface chemistry and rheological properties of API bentonite drilling fluid: $\mathrm{pH}$ effect, yield stress, zeta potential and ageing behaviour," Journal of Petroleum Science and Engineering, vol. 146, pp. 561-569, 2016.

[22] J. Fei, Hydraulics for Slurry and Granular Material Transport, Tsinghua University Press, Beijing, China, 1994. 